\section{Bell's Oral and Facial Pain (Formerly Bell's Orofacial Pain)}

Author(s)/Editor(s): Jeffrey P. Okeson

Publisher: Quintessence Publishing Co Inc

Language: English

ISBN: 978-0-86715-654-6

Edition: 7/e

Publish Year: 2014

Pages: 560, illustrated

Price: $\$ 98.00$

DOI: https://doi.org/10.25241/stomaeduj.2016.3(3-4).bookreview.2

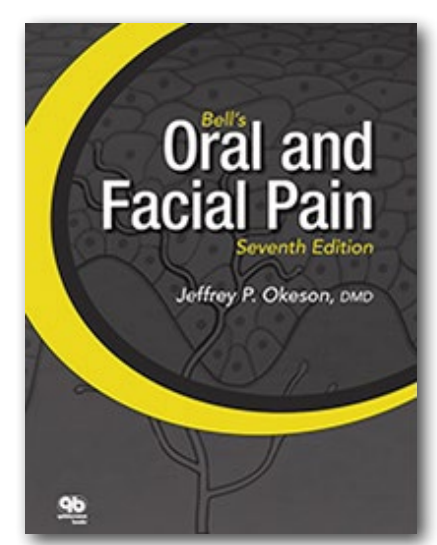

According to Dr. Welden E. Bell "pain is far more than a simple sensation; pain is an experience".Because pain is a major health care problem, research knowledge is expending exponentially. This revised edition incorporates the latest findings from neurophysiology studies and the central processing of pain, so the result is a new guide of diagnostics, classification, and treatment.

This textbook is divided into three major parts. Part One, namely "The Nature of Pain" has six chapters and presents the neural anatomy and physiology of the trigeminal system. Part Two, entitled "Clinical Considerations of Oral and Facial Pain" includes four chapters and presents the classifications of oral and facial pain and the diagnosis principles and therapeutic modalities. The nine chapters of Part Three, whose title is "Clinical Pain Syndromes" talk about cutaneous and mucogingival pain, dental pains, muscle pains, TMJ pains, musculoskeletal and visceral pain, vascular, neurovascular and neuropathic pains. Because the dental practitioners' interest in oral and facial pain disorders has increased, this textbook is very useful and provides the readers with information that will assist in resolving patients suffering from orofacial pain. This textbook is very well illustrated (260 illustrations) and for better understanding it is supplemented with case reports and full-color photographs and illustrations.

Bell's "Oral and Facial Pain" is addressed to the dental practitioners and the gnathologists interested in oral and facial pain disorders, the aim being to alleviate the suffering of TMD's patients.

The Books Review is drafted in the reviewer's sole wording and illustrates his opinions.

Marian-Vladimir Constantinescu $\mathrm{DDS}, \mathrm{PhD}$ ROPOSTURO - Holistic Dental Medicine Institute Bucharest, Romania e-mail: 